\title{
Moral Development
}

\author{
S Berges, Bilkent University, Ankara, Turkey
}

(c) 2012 Elsevier Inc. All rights reserved.

\section{Glossary}

Character trait A firm and stable disposition to behave

in certain ways across situations.

Developmental psychology The branch of

psychology concerned with the study of

progressive behavioral changes in individuals over a lifetime.

Ethics of care An ethical theory that emphasizes the role of relationships in determining the moral value of an action.
Kantian ethics A deontological ethical theory inspired by Immanuel Kant that emphasizes the role of reason and universal laws in moral judgment.

Utilitarianism A consequentialist ethical theory inspired by Jeremy Bentham and John Stuart Mill that starts from the principle that happiness is the greatest good and evaluates actions according to how well they promote happiness. Virtue ethics A type of ethical theory inspired by Plato and Aristotle that takes character, rather than actions, as the base for attributing values.

\section{What Is Moral Development?}

Moral development is a concept in moral psychology that has received at least as much attention in the past few decades from psychologists as from philosophers. The idea that there is such a thing as moral development relies on the following assumption: Whether or not there is an objective right and wrong out there, there is something that, as human beings, we take to be so, and we can be better or worse at recognizing and responding to appropriately. One important aspect of moral development is that we can teach ourselves and each other to become better at this, which means there is space for moral education of some form.

The theory of moral development has much in common with developmental psychology - that is, the study of how human beings evolve psychologically over their lives. Developmental psychologists claim that there is a way in which human beings typically develop: Some things we all learn to do at a certain age, just as we learn to walk. This can be studied, and the result of these studies can be used to assess the development of individuals and help those who have difficulties learning things they should at a particular stage, such as autistic children. So one of the main assumptions of developmental psychology is that there is a normal way for human beings to develop, a general path that our development should take, and that this is a natural process - most of us will get there whatever we do, without particular help.

It is arguable that both developmental psychology and theories of moral development originate from the same source, namely ancient philosophical theories of human development. For this reason, we can expect that theories of moral development will have much in common with developmental psychology. Theories of moral development claim that the development of moral attitudes can be traced and studied in individuals, in the same way that their psychological development can. However, unlike the ancients, we tend to view psychology as relatively value neutral, so it is likely that the two types of theories will diverge in places. In particular, whereas variance in psychological development is often accepted as natural (to some extent anyway), we tend to think that there is a right way to develop morally (even if we do not agree on what that way might be). For instance, it is perfectly acceptable for one child to be confident and impulsive and another to be quieter and more patient. However, it is not considered an acceptable state of affairs if the first of these children is dishonest and the second is violent toward others.

The relative value neutrality of psychological developmental theories also has implications for educational applications. We tend to think that education has a greater effect on moral development than it has on psychological development. At least some philosophers believe that whether or not we end up being a good person depends in great part on what and how we were taught.

Philosophers sometimes think of moral development as character development. For example, a child may become jealous of a new sibling and gradually replace this with more positive traits, such as love and care. These are character traits, a combination of beliefs and emotions that determine more or less reliably how one is likely to act in given circumstances (e.g., little Mary no longer tries to hurt her baby brother; she gives him sweets instead).

Another way of understanding moral development is to think of it as a growing understanding of moral theories or principles and how to apply them. Thus, for instance, 
little Mary now knows it is wrong to do bad things to her baby brother, that she has certain responsibilities toward him, and she understands that this implies she should share nice things with him and defend him against others who may wish to harm him. This way of understanding moral development gives reason the center stage, whereas the first way also appeals to emotions in an important way.

\section{Moral Development in Ancient Philosophy}

The idea that human beings develop morally had probably more currency among the ancient Greek philosophers than it does among contemporary analytic philosophers. It is central to the moral philosophy of Plato, Aristotle, and the Stoics. In all those cases, moral development is to be understood as character development - that is, becoming virtuous. However, this is not to say that the ancients did not believe that moral development depended on reason - quite the contrary - but that it depended also, and to a large extent, on emotional development.

For the ancients, to become good is to become virtuous, and that is a matter of developing certain firm character traits, the virtues, by training every element of one's soul - reason, emotions, and desires - to respond appropriately to situations. For them, moral development is character development. Modern psychologists, however, tend to be skeptical about character and character traits. Character traits cannot be measured, and they cannot be observed directly. If one is going to study moral development scientifically, then it is much easier to focus on behavior than on something that may or may not exist and of which behavior is supposedly a symptom.

Because of this, ancient theories of moral development, which focus mostly on character development, have received little attention from the more empirically minded moral psychologists. However, this is changing: Perceived weaknesses in the prevailing empirical theory of moral development have led philosophers to return to the theories of the ancients in order to explain how we become good. I will touch on this in the last section of this article.

Plato's thoughts on moral development are infamous. In The Republic, he advocates that the members of different social classes should be educated differently on the grounds that they are more or less capable of moral development. For example, members of the soldier class can hope to become courageous but not wise, whereas those of the class below (farmers and artisans) can only hope to develop a degree of temperance to enable them to control their unruly appetites so that they may follow orders more easily. Only the philosopher kings can hope to become fully virtuous. Thus, for Plato moral development is in the first place dependent on natural ability. Plato is very specific that what matters here is the size and influence of the three parts of the soul - reason, the emotions, and the bodily desires. Only if one's reason is strong enough to be in charge can one become fully virtuous. Someone for whom the predominant part is bodily desires will only be able, at best, to learn to control that part so that he or she may become less intemperate. However, this is only part of the story: In order for agents to develop to their full potential, Plato believes attention must be paid to their education. Different kinds of educational tactics will bring about different developments. Thus, for instance, storytelling, provided the stories focus on examples of people behaving as they should, can help train the part of the soul occupied by bodily desires. Mathematics, on the other hand, will help develop reason so that it can be prepared to contemplate Truth and Justice, the last necessary steps for becoming fully virtuous.

However plausible one may find Plato's intuitions that natural abilities and education both influence one's potential for development, his claims highlight a danger of taking moral development seriously: paternalism and state interference. Who will decide which of my natural abilities should and could be developed? What if I am a slow learner but am not given the chance of a proper education because the state has decided that I was not a good candidate for full development? What if, in the worst-case scenario, a child is branded a criminal because she displays some behavior that criminals have displayed in their youth? The potential for injustice and infringement of liberties is great here.

Maybe a less threatening approach to moral development as the development of the soul through education is to be found in Aristotle's concept of flourishing. Aristotle claims that in order to become virtuous, we must be habituated to respond in certain ways to certain situations from childhood. For example, little Mary must be told, again and again, to share her toys with her baby brother. When this is done well, Aristotle tells us, the behavior will become second nature; it will be effortless. After this, one must carry on practicing until not only is it effortless but also it has become enjoyable. So Mary will not have fully developed until she has learned the joy of giving and sharing. If she remains at a stage at which she feels obliged to share, or she knows she should share but somehow cannot bring herself to do it, then she has not developed properly. There is something highly intuitive about this. Imagine that as an adult Mary resents giving presents to friends and families for their birthdays but does it out of a sense of obligation: Wouldn't you think there was something not quite right about her? What Aristotle tells us is that knowing what the right thing to do and being prepared to do it is not quite enough: We have to feel that we want to do it as well. 
A less well-known but highly influential and enlightening theory of moral development is the Stoic theory of Oikeiosis. This term, sometimes translated as 'appropriation,' means roughly making oneself at home in the world, or identifying oneself with the world. The Stoics believed that in order to live a good life, human beings needed to come to love first themselves and, gradually, the entire human race. This natural process begins by learning to recognize the boundaries of one's own body and seeing to its survival and gradually embracing the world by learning to love first one's parents, other relatives, neighbors, compatriots, and everyone else.

What is deeply interesting and appealing about this theory for moral education is less the end, cosmopolitanism, than the nature of the process itself, making oneself at home in the world. Contrasted to Plato's very intellectual conception of moral development, and even Aristotle's with its equal emphasis on reason and the emotions, Oikeiosis is a holistic process that concerns the self as a whole. For the Stoics, a baby learning to suckle and a young adult beginning to empathize with the suffering of others are going through the same process - albeit at a different level of complexity. One drawback of such an all-embracing concept, of course, is that it is going to be very difficult to pin down exactly what it is that needs to be developed and how, so Stoic theories of moral development will remain vague and will have little applications for educational purposes.

\section{Moral Development in the Enlightenment}

Another significant historical moment for moral development is the Enlightenment. In the context of the French Revolution, much thought was given to education, with, at the forefront, the question of how to educate freethinking responsible citizens. Of particular interest are Rousseau and Wollstonecraft, who have slightly different takes on what it means to develop morally. Their differences meant that moral development would become a gender-sensitive issue.

Rousseau's thoughts on moral development are tied very closely to his theory of education. Rousseau believed that humanity was good by nature and that society made it bad. So the purpose of education was for him, in great part, to counteract the effects of society and to bring the child as close to nature as possible. Of course, Rousseau did not wish to bring humans back to a state of nature but thought that it should be possible, within a civil society, to preserve as much as possible of that natural goodness. This would start with the child being breast-fed by his or her own mother and continue with an outdoor education, with emphasis on learning through the senses.

However, like many of his contemporaries when they spoke of human nature, Rousseau thought that there was great difference between men and women. In particular, he believed that women were closer to nature and less able to learn abstractly, and that their main role in life was to please men. So girls are not encouraged by Rousseau to go beyond a 'natural' education. They should not study hard but, rather, learn to please with light conversation and to dress in an attractive manner, which are both skills that Rousseau believes come to women naturally. Politically speaking, this meant that when Talleyrand remodeled the national curriculum after the revolution, he settled on two different programs for boys and girls, with less emphasis on academic skills for the latter.

Both an admirer and a critique of Rousseau, Mary Wollstonecraft devoted her career to proving him wrong. Reason is what drives human nature, she said, and reason is not male - it is divine. So Rousseau is wrong to claim that women are not capable of developing in the same way as men. What he is right about is that eighteenth-century women on the whole do not behave as if they were reasonable beings. They are frivolous, concerned with their looks more than bringing up their children or doing anything useful, and incapable of sustained abstract thought. But this, Wollstonecraft argued, has less to do with their nature than with the poor education they have received. Any human being, she says, male or female, has the potential to develop into a moral being and a useful member of society provided they are educated in a rational manner.

In this she echoes Kant's appeal for better education for the purpose of general enlightenment. If human beings are in chains, it is not so much because society enslaves them as that they will not think for themselves. But thinking for oneself is, of course, difficult and even frightening. If one is not used to doing so, it may just be easier to let oneself be directed by some other authority. So what is needed in order to achieve moral and intellectual maturity is an early education that encourages children to think for themselves - to use their reason in adventurous ways. Wollstonecraft saw that this kind of education was sorely missing from the upbringing of girls, who were left to their own devices, taught only to dress and gossip, and married off early, thus taking their cue from their husbands rather than having the opportunity to learn to live in the world for themselves.

\section{Piaget and Kohlberg}

One very influential, recent theory of moral development that turns its back on character development is that of Lawrence Kohlberg. He defends a stage developmental theory, meaning that he believes that our moral responses evolve in an orderly and increasingly adaptive manner through a series of stages. His theory is modeled on Piaget's theory of cognitive development and draws 
both strength from the parallels it is able to draw and weakness from those it cannot. For this reason, it is useful to briefly discuss Piaget's theory.

A developmental psychological theory is one that is in some sense between nativist and empiricist theories. A nativist theory emphasizes the importance of heredity and the innate structure of the mind (Descartes and Fodor), whereas an empiricist theory adopts the tabula rasa view of the mind - the view that mind is shaped solely by experience with maybe the exception of a few structuring principles (Hume and Skinner). Piaget's theory of the mind incorporates aspects from both these extremes, including a rich innate structure of the mind, a normal biological maturation determined by that structure, the processing of experience, and the tendency of biological systems to organize experience and adapt to reality.

Piaget's claim that cognitive development happens in stages is defined by a set of criteria of what it is for something to count as a stage:

1. Universality: All stages must be found in all cultures, and all normal individuals must reach the highest stage.

2. Structured wholes: A stage is a logically homogeneous and coherent set of concepts and structures, with each stage integrating the competences acquired in the previous ones.

3. Invariant sequence: All individuals go through each stage in the same order; there is no possibility of skipping a stage.

4. No regression: Unless there is physiological damage to the brain, it is not possible to go back to an earlier stage.

Piaget identifies four stages that clearly define what a child's understanding of the world should be in any given age group, from getting a sense of one's body and its place in the world up to 2 years of age to becoming proficient at manipulating second-order representations from 11 years onward.

An important part of Piaget's theory is the adequacy thesis, namely the claim that each stage is more complex and a better fit for the world than the previous one. Because each stage can be matched with an epistemological theory, Piaget believes that his claims have philosophical value. The cognitive development of a 2year-old is solipsistic, and that of a 7-year-old is relativist. Only once we reach the final stage do we become epistemological realists. Because the final stage is a better fit to the world, because we have maximally adapted when we reach it, then realism is a superior position than relativism and solipsism.

Although objections have been raised against Piaget, particularly about the nature of his experiments (Do young children react in the same way to men in white coats as older children? And if not, does it falsify the results of the experiments?), there is much evidence that he is in fact correct and that our ability to process experience about the world evolves in ordered, nonreversible stages. At the very least, there seems to be a major difference between the ways in which different age groups typically process experience. This does not mean that Piaget's views are generally accepted: Very few psychologists are in the business of proposing such general theories of mental development, preferring to focus their claims on particular domains.

Yet the fact that Piaget's theory of cognitive development is overall pretty convincing seems to be a good reason for Kohlberg to want to use it as a model for his theory of moral development. However, although some of the most convincing aspects of Kohlberg's view can be traced back to the plausibility of Piaget's theory, the lack of symmetry in some aspects means that Kohlberg's view is much less convincing than Piaget's.

Kohlberg describes six stages of development, from egocentrism and relativism to more altruistic, contractual, and principle-led moral thinking. Children start off caring only for themselves and end up as adults, either as utilitarians or Kantians, depending on how much they have evolved. This means that they will form moral judgments or make moral decisions on the basis of rules that they perceive as applying to all, either rules dictated by the general principle that happiness is the greatest good or, if they are Kantians, rules derived from reason and the principle of universality.

The transition between stages as Kohlberg describes it is done according to a constructive process. We attempt to solve moral problems we encounter within a system, following a set of rules we know we can rely on to give adequate solutions. However, if we encounter a problem that cannot be dealt with within that system, we adapt and the system evolves into the next stage.

This process of natural maturation means that ultimately moral wisdom cannot be taught theoretically only: We need experience to test for ourselves the limits of our moral structures. Of course, moral theory may well help us choose a more adequate framework for solving problems. People faced with something evil for the first time will probably want to give up a relativistic view of the moral world, and in order to evolve, they might well start by turning back to the rules and principles they learned as children from their parents, their church, etc. Reflecting on these will then lead to a system of rules and principles that reflects the individual's responses to situations. They will have evolved to the next stage.

These two claims - that there is a general progression from ego-centrism toward altruism and that morality must be discovered through experience rather than taught - are very plausible indeed, at least on an intuitive level. However, they are not sufficient evidence for accepting the entirety of Kohlberg's developmental theory - they only give us the very loose structure of a theory, one that could just as well be filled with an Aristotelian theory of 
habituation as with Piaget-style stages of moral development. In fact, there are many reasons why we should be cautious in accepting any of the detail Kohlberg uses to develop his theory further. In the next section, we discuss the main problems with Kohlberg's view.

\section{Problems with Kohlberg's Theory}

Three main types of objections have been raised against Kohlberg's theory of moral development. First, the experiments he uses to derive his claims are not obviously testing what they are supposed to be testing. Second, it is not clear that Kohlberg stages are stages in the sense that Piaget's are stages and, therefore, that Kohlberg's theory really is a developmental theory. Third, Kohlberg's adequacy thesis (i.e., the thesis that the last stage of development is somehow higher than earlier ones) depends on a picture of moral theories that is far from complete and is not therefore conclusive.

\section{The Bad Experiments Objection}

Kohlberg's experimental paradigm is problematic on at least three levels. Subjects of the experiment are presented with a set of moral dilemmas and asked what the protagonist of the dilemma should do. The experiments appear to be testing verbal reports, but it is not clear what competence these reports are supposed to represent. Are the subjects supposed to guess what the person in the dilemma will do, to make a judgment as to what that person should do, or to state what they would do if they were in that dilemma?

Another problem with the nature of Kohlberg's experiment is that the data are purely verbal, whereas morality is not - it has to do with actions. Even if we take the subjects' answers to reflect their beliefs about what they would do in the situation presented, it does not follow that the experiment measures in any way people's moral behavior. There is indeed good experimental evidence that there is a gap between what people say they will do in a given situation and what they actually do when faced with the situation in question: It is not just that people like to give a flattering picture of themselves but also that they are not very good at predicting their own reactions.

This particular worry outlines an important asymmetry between Kohlberg and Piaget's theories. Piaget's experiments test a child's actual behavior when confronted with an actual situation. Kohlberg's experiments fall very short of this in testing verbal behavior about a hypothetical situation. Thus, Kohlberg's conclusions are weaker than Piaget's.

Last, it is not clear that the experiments devised by Kohlberg provide a full or even reliable test for moral competence because the concept of morality underlying them is incomplete. The experiments draw upon dilemmas presenting two or three possible options rather than real complex moral problems such as individuals are likely to be called to act on. Also, all these dilemmas tend to focus primarily on questions of fairness and distributive justice. As a result, they pay less attention to, for example, questions of courage, generosity, loyalty, and many areas of morality that make up our everyday moral world. Because of this, it is hardly surprising that Kohlberg's conclusions favor Kantian ethics and Rawlsian politics. It seems the experiments are rigged.

\section{The Stages Criteria Objection}

Piaget is able to derive firm conclusions from his theory in part because he has devised strong criteria for a theory to count as developmental. For the conclusions to be reliable, the science must be rigorous. In using Piaget as a model, Kohlberg is riding on the back of this reliability. Unfortunately, however, in recasting the theory in the moral domain, he loses some of Piaget's rigor. In other words, it is not clear that Kohlberg's theory can be classified as a developmental stage theory because his stages fail to satisfy Piaget's criteria of universality: being structured wholes, of invariant sequence, without regression, and integrated.

Let us take two of these in particular, invariant sequence and regression, in order to understand the extent of the problem. For Piaget, one important condition is that it should be the case that each and every person goes through each stage from the first to the last, in the right order. This raises two different problems for Kohlberg. First, it is not clear that according to Kohlberg, each and every individual reaches the final stage of morality (i.e., the Kantian stage). He equivocates on this by saying that most people will reach either stage 5 or stage 6 . He sometimes questions whether anyone ever reaches stage 6 . He is also not confident that in non-Western, nondeveloped countries, people reach stage 5 at all they remain at the relativist stage.

Second, there is room in morality for an individual to leap from a relatively low understanding of what it means to be moral to an almost saintly disposition. One such example, of course, is Saint Augustine, who from being a libertine became highly religious. From his memoirs, it seems that both his beliefs and certainly his behavior changed dramatically at one point in his life, without going through a set of ordered stages. This is true of most conversion stories, religious or not. People may well decide one day to mend their ways, and if they are successful, they will behave in a totally different way for the rest of their lives. No such thing is possible for cognitive development. A 3-year-old child cannot decide suddenly to understand abstract operations; the child 
needs to go through the right stages (even if he or she goes through them faster than other children).

With regard to regression, again there is room for considerable doubt as to whether Kohlberg's stages follow the same model as Piaget's. Commonsense observation tells us that people do in fact regress morally, quite often. In particular, it has been observed that whereas adolescents will develop highly principled and universal moral systems, they will often revert to relativism once they have jobs and families of their own. This is the hippie-turned businessman phenomenon: Idealistic values sometimes do not seem worth holding onto when there is money to be made. In defense of Kohlberg, we could reply that those values probably were not very solidly held if they were so easy to give up later in life. But that will not work for two reasons. First, many middle-aged people express acute regret at having had to give up their old values; they wish they were still the same people and feel in many ways diminished. Second, the stage criteria define stages as presenting different structures for processing experience but say nothing about the seriousness of one's involvement with those structures.

\section{The Adequacy Thesis Objection}

Finally, we should say something about how Kohlberg's adequacy thesis is not strong enough to support the psychological and the philosophical conclusions he wants to draw from it. The thesis, in parallel to Piaget's, states that the more psychologically advanced stage of moral development is also the morally more adequate. Thus, if stage 5 is Mill and stage 6 is Kant, then Kant's moral philosophy is more advanced than Mill's.

Even if we accept that Kohlberg is correct as to what the stages are and which one is more advanced, he can only draw parallel philosophical conclusions about whether or not the stages actually represent the whole of moral philosophy, and do so accurately. However, this is clearly not the case. Not only do his characterizations leave out many aspects of moral reasoning that philosophers are concerned with but also they do not even address the broad lines of the main moral theories available.

As we saw, the experiments Kohlberg conducts are based on subjects' responses to dilemmas about distributive justice - but that is only a very small part of what morality is about and what moral philosophy discusses. If we want to know which theory will help us deal best with moral decisions, we need a larger range, something that enables us to address questions about how to be a good parent, a good friend, and a good citizen. We discuss this gap in Kohlberg's theory in the next section.

\section{Alternatives to Kohlberg: Care and Virtue}

One famous critique of Kohlberg's theory of moral development is Carol Gilligan's In a Different Voice. In that book, she argues that most moral theories tend to focus on justice and contract theories, which are traditionally male concerns, and at the same time ignore and trivialize issues and values traditionally associated with women. Gilligan notes that in Kohlberg's experimental setup, women rarely get past level 3, whereas men have no difficulty reaching level 4 , or even level 5 , and have a good chance of reaching level 6. Does this mean that women are less morally developed than men, that they are not as capable of becoming moral beings?

There is, of course, another way of looking at these findings: Level 3, with its emphasis on taking into account the well-being of others as well as one's own, is actually quite a good way of thinking morally, one that has merits that those who prefer levels 4 and 5 fail to see. One could say, of course, that Kohlberg just got it wrong - that there is little value in a Kantian way of thinking and that what women do is the best way to be. However, Gilligan prefers to say that women simply speak in a different voice. There are different ways of being moral, different emphases, and women typically prefer to be caring and men impartial.

Gilligan has started to argue, following studies of the moral development of men, that at least for some men, level 3 may also be best, but that society tends to stifle men's caring impulses.

An objection to Gilligan's critique is that we do not need to turn to 'care ethics' in order to be caring individuals. Theories of justice incorporate principles of caring. For example, 'protect your children from harm' is presumably a perfectly good Kantian principle, and it certainly works for utilitarianism. However, having that principle is not enough to be caring - we need to know how and when to apply it. Consider, for instance, two sets of parents. One decides never to let their child go out with friends because they are concerned that if they do their child might drink alcohol, take drugs, and have (unprotected) sex. Contrast this to the parents who notice that their child is going through a difficult time, which makes him or her potentially more vulnerable to such dangers, and who respond to this by being supportive throughout that time (even if that means being tough to be kind). Only the second parents, I think, are really caring, although both try to be.

This characterization of what it means to protect one's children from harm is Aristotelian in that it emphasizes the importance of practical reasoning - that is, noticing relevant aspects of situations, working out what is required from us, having appropriate emotional reactions, knowing when to be angry, when to be worried, and, conversely, when not to be. 
The previous objection is one very good reason why some philosophers interested in care ethics have tried to link it to virtue ethics. Gilligan's third stage could be virtue ethics. Incidentally, this is a moral theory that Kohlberg completely leaves out of his analysis. In fact, virtue ethics is now regarded significant enough to be considered a serious competitor to both Kant and Mill, so that might be reason enough for Kohlberg to reconsider his classification of the stages.

Another objection to Gilligan is that no more than Kohlberg does she provide an account of human development. Her stages do not fulfill Piaget's criteria. We may have to bite the bullet and accept that it is not possible to develop a theory of moral development that works along the same lines as Piaget's theory of cognitive development. It may just be that psychology and experiments cannot help us determine exactly what it means for a human being to develop morally. If that is the case, then it is useful to turn back to moral theories that contain some account of what it means to become moral and how typically that will work. This is certainly what Aristotelian ethics does, but there may be other options. We cannot rule out the possibility of an equally plausible account of moral development coming from a Kantian or a utilitarian perspective.

\section{New Directions for Moral Development?}

Before Kohlberg, no one had attempted to provide a full and systematic account of moral development. For the Ancients, as well as for the philosophers of the Enlightenment, moral development was part of moral theory in general, not something to be discussed at length and separately. Kohlberg's account, on the one hand, takes moral philosophy as a given. Although he seems to believe that his theory can prove or disprove a moral theory (Kantian ethics turns out to be the superior theory on his account), it does not presuppose a particular one. This approach has many strong points. First, it enables Kohlberg to focus on the question of how we become moral rather than treating it as an aside. In particular, it means that Kohlberg can look to developmental psychology and attempt to apply scientific findings to a philosophical problem. It is much more difficult to do this from within the confines of a philosophical system such as Plato's or Aristotle's.
On the other hand, it seems that moral philosophy has more to say about development than Kohlberg gives it credit for. What we are looking to test - character, actions, and life choices - will depend quite a lot on which theory we embrace in the first place. Gilligan's critique of Kohlberg shows just that: His rankings presuppose that Kant was correct and that Mill was a close second rather than show as much. Although it may be difficult to develop a theory of moral development that is neutral with regard to choosing a moral theory, at least a certain awareness that this is the case, and that there may be alternative theories of development supported by rival moral theories, is surely needed. Once we have this, then there is room for competing theories of moral development, and maybe even a virtue ethical theory of moral development.

See also: Aristotelian Ethics; Care, Ethics of; Feminist Ethics; Kantianism; Platonism; Stoicism; Theories of Ethics, Overview.

\section{Further Reading}

Aristotle (1976) The Nicomachean Ethics, Thomson JAK (trans.). In: Barnes J (ed.) Harmondsworth, UK: Penguin Classics. Brennan T (2003) Stoic moral psychology. In: Inwood B (ed.) The Cambridge Companion to The Stoics, pp. 257-294. Cambridge, UK: Cambridge University Press.

Flanagan O (1984) The Science of the Mind. Cambridge, MA: MIT Press. Gilligan C (1982) In a Different Voice. Cambridge, MA: Harvard University Press.

Reiss W (ed.) (1991) Kant's Political Writings. Cambridge, UK: Cambridge University Press.

Kohlberg L (1981) Essays on Moral Development. San Francisco: Harper \& Row.

Plato (1992) The Republic, Grube GM (trans.). Indianapolis, IN: Hackett. Rousseau J-J (1993) Emile. Cole GDH (trans.), Dent JM (ed.), London: Everyman.

Wollstonecraft M (1994) A Vindication of the Rights of Woman; $A$ Vindication of the Rights of Men. Oxford: Oxford University Press.

\section{Biographical Sketch}

Sandrine Berges obtained a B.A. and a M.Phil. in Philosophy from the University of London and a Ph.D. in Philosophy from the University of Leeds. She currently lectures in the philosophy department at Bilkent University. Her most recent publication is Plato on Virtue and the Law (Continuum). She focuses on ethics and particularly moral psychology in the Plato, Wollstonecraft, Nietzsche, and contemporary virtue ethics. 